\title{
Representações da Cidade Contemporânea
}

\author{
Representations of the Contemporary City
}

\author{
> Gilberto Corso Pereira \\ Universidade Federal da Bahia, Brasil \\ corso@ufba.br
}

\begin{abstract}
Representation is a key concept for understanding the social uses of technologies associated with manipulation, presentation, storage and maintenance of geographic information. This paper refers to forms of space representation, essentially derived from cartographic techniques, that bases many web applications which aid to promote the development of new forms of social interaction and influence the perception and use of public spaces. The paper discusses the relationship between spatial representation, spatial knowledge and technologies of representation and visualization of space.
\end{abstract}

Keywords: Representação socioespacial; Informações Urbanas; Representação do Espaço Urbano; Digitalização do Espaço Urbano

\section{Introdução}

As cidades são organizaçôes complexas e planejar e gerir o seu crescimento necessariamente envolve uma série de conhecimentos diversos e uso de processos e ferramentas sofisticadas. A idéia de planejar o crescimento ou evolução de uma cidade pressupóe a possibilidade de aprender a antecipar e evitar problemas associados ao seu desenvolvimento. Também exige conhecer as necessidades e exigências de instalaçóes ou serviços públicos - habitação, transporte, saneamento, infra-estrutura, legislação, etc - e as formas de minimizar ou corrigir essas deficiências. Em um mundo cada vez mais urbanizado a complexidade de variáveis que influenciam a análise aumenta à medida que as cidades se expandem e o tecido urbano se transforma.

Análise espacial urbana executada para fins de planejamento urbano trabalha com um grande volume de dados. Os dados digitais são pressuposto para a criaçáo de representaçóes digitais. As tecnologias digitais possibilitam tanto a leitura e análise das realidades urbanas quanto a sua comunicação entre os vários atores sociais - cidadáos, organizaçóes, empresas - permitindo o acesso e uso da informaçáo. Por outro lado, o uso de representaçóes digitais permite a participação do público, mas também a manipulação da opinião pública.

Representação é um conceito chave para entender o uso de tecnologias associadas à manipulação, apresentação, armazenagem e manutenção de informaçóes geográficas. Representaçôes espaciais se tornaram uma característica comum em aplicativos em dispositivos móveis e plataformas de redes sociais.

Hoje existe um conjunto de tecnologias disponíveis para produzir uma grande quantidade de informaçóes sobre a cidade provenientes do processamento de dados tanto de atividades humanas, quanto de sistemas automatizados. Ao permitir a interação do usuário com representações do ambiente físico e ampla troca de informaçôes entre eles, as tecnologias de informação e comunicação possibilitam envolvimento dos indivíduos em atividades participativas, como mapeamento colaborativo e crowdsourcing, uso de aplicativos de redes geográficas e sociais em dispositivos móveis, aplicações de realidade aumentada, para citar algumas possibilidades.

O surgimento e consolidaçáo de uma cultura digital, por sua vez, traz novas discussóes sobre formas de representação do espaço urbano, que devem abordar a representaçáo dos acontecimentos e processos contemporâneos colocando em questão o estabelecimento de fronteiras entre o físico e o digital (Sassen, 2001).

As técnicas de representação acompanham o desenvolvimento tecnológico. As ferramentas CAD (Computer Aided Design ou Drawing) permitem construir e gerar modelos geométricos de objetos que podem ser vistos em diferentes pontos de vista. Em paralelo ao desenvolvimento de sistemas CAD, o surgimento e desenvolvimento dos SIGs - Sistemas de Informação Geográficas - trouxeram um avanço nas representações do mundo. As ferramentas SIG permitiram que, além de uma representação geométrica do mundo, com base na utilização de elementos geométricos simples como os pontos, linhas e polígonos usados na cartografia tradicional (mais tarde superfícies e volumes), atributos não-gráficos fossem adicionados a esses elementos, vinculando o simbólico à representação geométrica. A Geografia é entâo representada por um banco de dados que contém dados sobre a geometria dos objetos representados e seus muitos atributos possíveis. 
As ferramentas de projeto de Arquitetura e Engenharia também evoluíram para modelos que vão alem da representação geométrica. Um Modelo de Informações do Edificio, ou BIM (Building Information Model) pode ser definido como um modelo de construçáo digital tridimensional semanticamente rico e compartilhado e que vai além do modelo icônico. Modelos BIM podem ser integrados numa representaçáo geográfica urbana como argumenta Isikdag (2011).

Ferramentas de SIG também introduzem a idéia de representação do meio ambiente através de grades ou matrizes, representando não apenas objetos no espaço mas o espaço em si de uma forma consistente com a possibilidade de que cada parte da superfície da terra pode ser captada por sensores remotos (Batty, 2007).

Hoje convivemos com o espaço urbano plenamente digitalizado e temos acesso a representaçáo da realidade física da Arquitetura e das cidades geométrica ou topográfica com alto realismo e baixo nível de abstração. Uma consequência disso, é o surgimento de várias "cidades virtuais" criadas utilizando várias técnicas e acessíveis na web através de serviços como o Google Earth, Virtual Earth, World Wind.

\section{Representações do espaço urbano}

Mapas vem sendo usados como uma ferramenta de apoio à investigação de questôes espaciais há muito tempo. Harvey (1993) e Söderström (1996) apontavam a importância da invenção da perspectiva no Renascimento e as inovaçóes que esta tecnologia trouxe nas técnicas de representação por permitir capturar o espaço como um todo, através da representação de feições geográficas até impossíveis com as técnicas cartográficas da Idade Média.

A possibilidade de usar cartografia não para trazer informação sobre o espaço, mas para espacializar as informaçóes surge muito depois. Gordon e Silva (2011) usam o exemplo do notável mapa da cólera de John Snow para ilustrar este momento. A diferença de enfoque "informação sobre o espaço" ou "informação no espaço" é que o primeiro usa os dados para conferir sentido à geografia e o segundo usa a geografia para trazer significado aos dados. Tuftle (2002) usa a mesma imagem, apresentada na figura 1, para ilustrar a importância da representaçáo espacial das informaçóes na tomada de decisóes.

As ferramentas atuais para profissionais de Arquitetura, Urbanismo e Geografia permitem a criação e manipulação de modelos que representam o mundo físico - infra-estrutura urbana, redes, edificaçôes e ambiente - alem de aspectos simplificados das relaçóes sócio-econômicas. São representaçóes digitais sobre o espaço urbano com base na descrição geométrica dos aspectos físicos das cidades e têm uma enorme importância para um grande número de atividades de Planejamento, Engenharia, Arquitetura e Urbanismo, mas não conseguem capturar aspectos importantes da vida cotidiana e o surgimento de novos tipos de espaço público. "Os arquitetos e urbanistas da era digital devem começar por re-teorizar o corpo no espaço” (Mitchell, 2000).

Sassen levanta a questão de que as representaçôes topográficas, ou seja, representaçóes da realidade física, náo conseguem captar a essência das relaçóes econômicas, políticas e culturais da cidade contemporânea (Sassen, 2001). A simples distinção de categorias convencionais: físico x digital não responde ao que acontece na sociedade de hoje.

As representaçóes tradicionais de aspectos sociais e demográficos nas cidades são baseadas na agregação de pessoas ou famílias em áreas

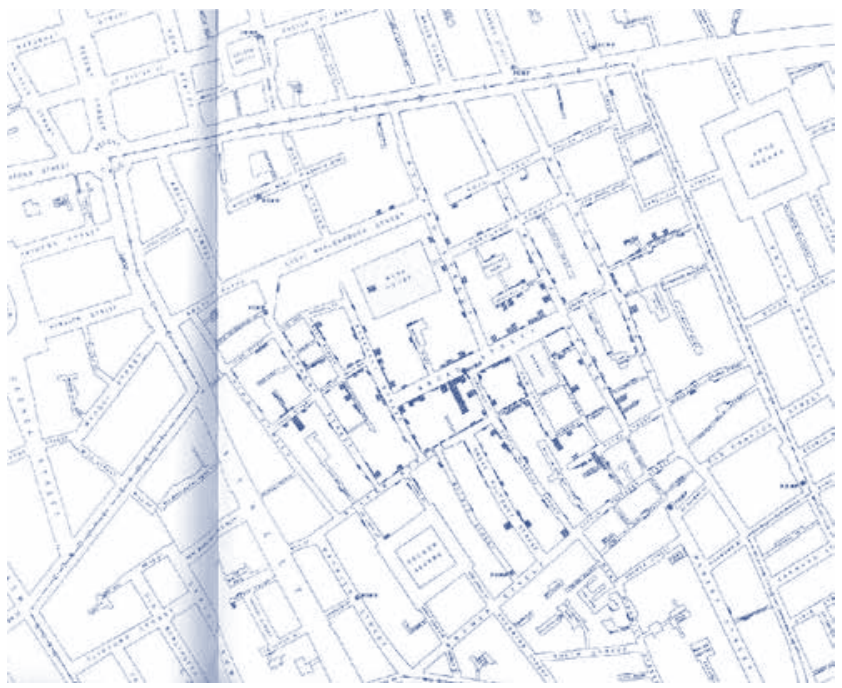

Figura l: Informação no Espaço. Mapa da Cólera, John Snow. Tufte (2002).

definidas e uniformemente representadas (setores censitários, por exemplo) ou no endereço físico de indivíduos. No primeiro caso, aplicaçôes baseadas em geodemografia, a geometria básica associada com a representação social é uma área, no segundo, que lida com universos mais restritos, o tratamento é pontual (domicilio, por exemplo). Nos dois casos é uma representação topográfica que fornece a base para a representação social. A figura 2 ilustra este enfoque com uma representaçáo dos tipos de habitação em Salvador, elaborada por Pereira (2008) a partir de dados do censo demográfico de 2000.

Embora essa forma de tratamento de dados e informaçóes mantenha a sua relevância, as redes sociais digitais contemporâneas

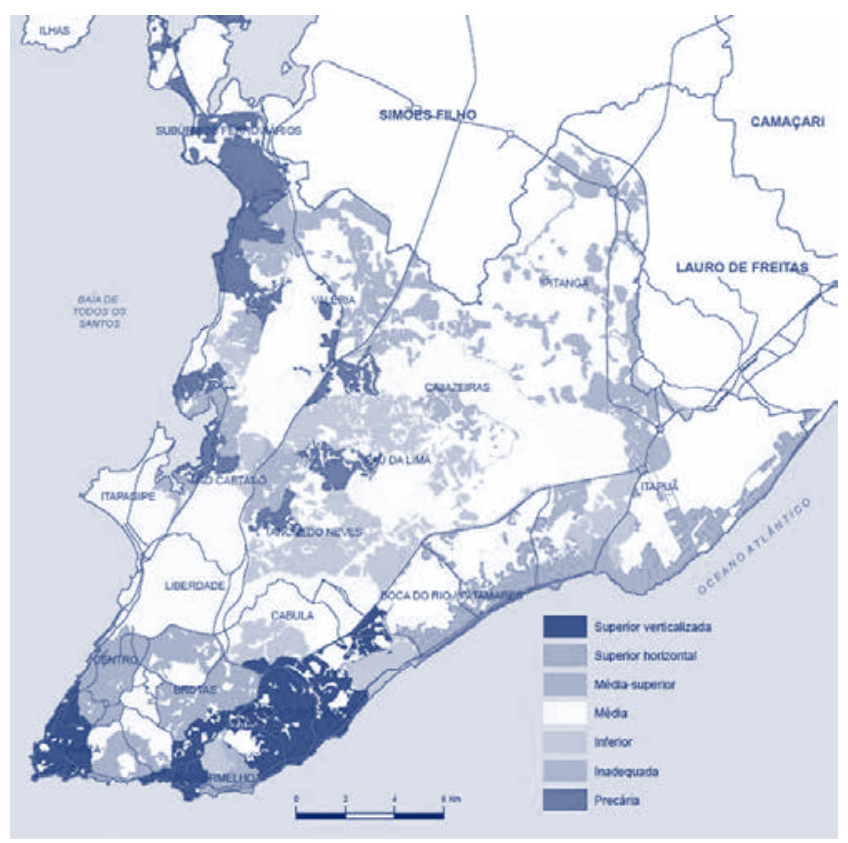

Figura 2: Representação de Informaçôes SocioDemográficas. Tipologia Habitacional de Salvador. Pereira (2008). 
começam a desempenhar um papel estrutural na sociedade. Isto traz novos desafios para a construçáo de representaçóes espaciais da sociedade e de suas relaçôes, com implicaçôes nas áreas que trabalham com dados geodemográficos (Singleton e Longley, 2009) como planejamento e gestáo urbana. Afinal, para o planejamento urbano é necessário gerenciar e entender o "fixo" - estrutura e infra-estrutura física - e os "fluxos" - mobilidade, transporte, e acrescentar agora fluxos de conteúdo digital.

A grande maioria das formas de representação de informaçóes urbanas usadas hoje continuam baseadas em técnicas cartográficas simples. Mas hoje sobre estas representaçóes podemos agregar dados online em tempo real. A representação pode ser dinâmica, mostrar a evolução de processos, como por exemplo, a mobilidade das pessoas na cidade, a situação do tráfego ou o fluxo de informação em redes sociais, e ser acessada durante a jornada ou atualizada e modificada pelos cidadáos que atuam como consumidores e produtores de informação espacial como mostrou Goodchild (2007).

A figura 3 mostra um exemplo disto. Waze é um software de navegaçáo desenvolvida pela Waze Mobile para smartphones equipados com GPS. Alem das funcionalidades já comuns em outros aplicativos similares tais como, informaçóes sobre a rota e alertas específicos sobre locais determinados, o aplicativo manda informação anônima sobre velocidade e localização dos usuários e com isso melhora a precisão das informaçóes do sistema como um todo. Como o web site do aplicativo (www.waze.com) declara "tráfego é mais do que apenas linhas vermelhas no mapa”. A aplicação poderia ser caracterizada como um software social de navegaçáo e uma comunidade crowdsourcing. A interface é baseada em um mapa dinâmico e em algumas convençóes gráficas semelhantes a jogos para apresentar as informaçóes.

Neste caso a representação é modificada dinamicamente a partir do movimento do viajante que ao se deslocar acrescenta dados novos que são incorporados na representação do local que uma visão do espaço mais ampla. O usuário está no local e no mapa e colabora para a construção do último.

\section{Considerações finais}

Os diferentes estágios de desenvolvimento tecnológico sempre se refletem no espaço urbano e na composição das cidades, isto acontece de diversos modos. As tecnologias de transporte e o aumento na

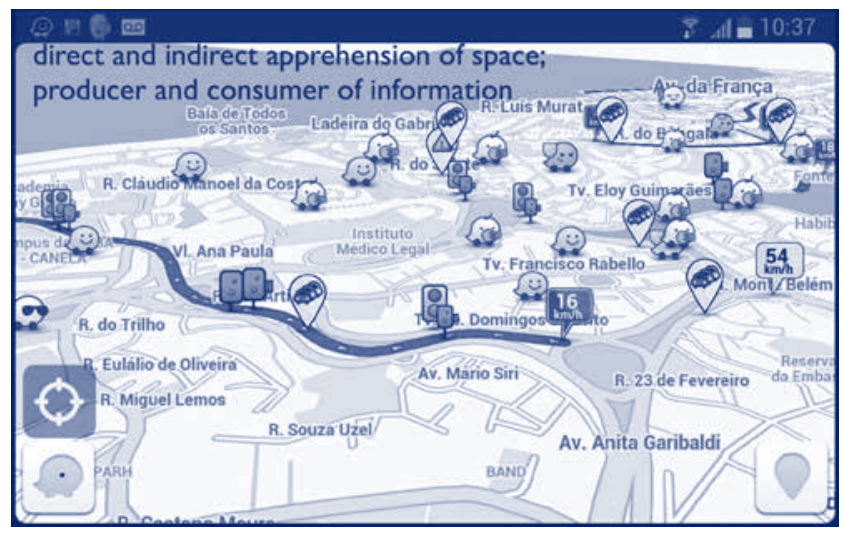

Figura Э: waze.com. velocidade dos deslocamentos levou a uma maior dispersão, o surgimento do telefone reformatou a cidade permitindo, dentre outras coisas, a separação da fábrica e dos escritórios. A televisão possibilitou que um mesmo evento acontecesse simultaneamente em dois lugares, na fonte da transmissão e nos diversos receptores dos sinais de TV.

Podemos considerar as organizaçóes sociais e redes sócio-técnicas como sistemas e ambientes com formaçóes de diversas escalas e dependentes de tecnologias digitais, cruzando uma variedade de fronteiras, gerando uma gama de práticas espaciais, organizacionais e de interação até então inexistentes (Latham, Sassen, 2005).

Hoje os cidadãos são capazes de registrar e divulgar as suas impressôes e estas podem ser ancoradas na própria cidade. Planejadores devem reconhecer que agora a nossa experiência urbana não é apenas influenciada pela forma urbana, mas por diferentes meios e formas de comunicaçáo com as quais interagimos diariamente. A cidade se tornou uma grande e contemporânea interface que inclui e exclui os cidadáos conforme eles tenham acesso (ou não) a dispositivos portáteis avançados. O flaneur tem uma nova janela para experimentar a cidade, mesmo considerando que muitas vezes seja necessário o uso de um cartão de crédito.

Enquanto as interações entre as redes sociais são reforçadas e contribuem para organizar a vida urbana cotidiana e a sociabilidade e mais do que isso tornando mandatário a posse de dispositivos portáteis para acessar as interfaces distribuídas na infra-estrutura urbana. Podemos dizer que hoje os espaços digitais não são mais virtuais e o acessos a certas facilidades da cidade contemporânea é viabilizado àqueles que tem os meios com os requisitos de conectividade e ubiquidade que mudaram o modo pelo qual nos comunicamos na última década. Segundo Benkler (2006) as práticas sociais presentes na cultura digital atual são mais auto-reflexivas e participativas. Este autor sugere que s o crescimento da habilidade dos indivíduos em se conectar em redes está no centro das forças que impulsionam o crescimento da economia informacional conectada.

As interaçôes sociais da vida cotidiana estão de fato permeadas pelas tecnologias digitais. Os exemplos dos usos atuais das formas de representação espacial indicam uma possível mudança na percepção

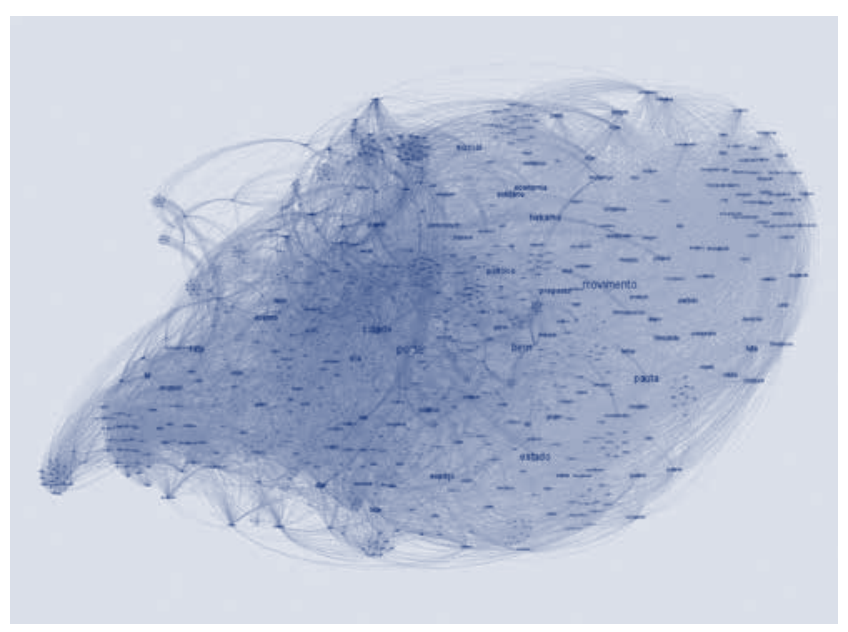

Figura 4: Rede de palavras de grupos que atuam no espaço urbano. Rocha, Florentino, Pereira, 2014. 
dos contextos pelo compartilhamento social e pela crescente integraçáo dinâmica das informaçóes. As questóes relacionadas à representação e conhecimento do espaço podem ser sumariadas num ciclo que leva à representação do conhecimento com o uso de tecnologia que por sua vez levam ao enriquecimento do contexto e conhecimento do local. A convergência tecnológica e a ubiquidade das conexóes está promovendo um conjunto de práticas socioculturais que agregam novos significados à informação com a ampliação da produção do que chamamos "informação no espaço".

As implicaçóes destas mudanças são ao mesmo tempo culturais e tecnológicas, restaurando aqui o velho argumento de McLuhan, “o meio é a mensagem”, devem ser consideradas nas práticas atuais de planejamento urbano. As previsóes que apontavam para a irrelevância do senso de localização geográfica, com o espaço geográfico substituído pelo ciberespaço, e a dicotomia entre o virtual/digital $\mathrm{x}$ real/físico estáo sendo superadas pela sobreposição ou convergência entre ambientes físicos e digitais. Além do uso dessas tecnologias de comunicação e interaçáo social enfrentamos o surgimento do que alguns autores chamam de "urban computing" ou "everyware" (Greenfield, 2006; Kitchin \& Dodge, 2011) - a capacidade de processar dados e informaçóes embutidos na infra-estrutura urbana onde ao contrário do conceito de ciberespaço - um espaço virtual de comunicação - a localização geográfica desempenha um papel central porque as interaçôes são baseadas em "onde" você está.

As atividades de planejamento ainda têm que lidar com a estrutura e infra- estrutura física das cidades. Espaços públicos, praças, ruas, espaços privados, a mobilidade, a densidade, a segregação, a regulamentação do uso da terra continuam a ser relevantes para a gestáo e exploração da cidade, mas é necessário adicionar novas ferramentas que podem mostrar e gerir os fluxos de informação, conectando negócios, governamentais e não governamentais e, especialmente, os cidadãos, que a partir dessas possibilidades culturais e tecnológicas podem atuar, também, politicamente e influenciar o modo de pensar e agir sobre essas estruturas, tanto física quanto digital.

Plataformas desenvolvidas com tecnologias cada vez mais onipresentes, fáceis de usar e econômicas, juntamente com o surgimento de uma nova cultura tecnológica iniciada com o advento da chamada web 2.0, poderiam ser hoje utilizadas como poderosos instrumentos auxiliares de planejamento participativo, permitindo que o usuário visualize e interaja com os contextos, com os dados, e incorpore a dimensão temporal na análise do espaço. Portanto, é possível usar esses recursos na avaliação de cenários, na discussão de alternativas e compartilhamento de idéias e até mesmo experimentar a sua capacidade de estimular os cidadáos a estabelecer interaçóes sociais, cívicas e democráticas, como uma espécie de governança mediada pela Internet.

Pesquisas em curso na Universidade Federal da Bahia (Rocha, Florentino, Pereira, 2014) investigam o uso das tecnologias digitais móveis e sua influência no ambiente urbano explorando como dados disponíveis de redes sociais digitais podem ser usados para compreender as açóes coletivas em curso sobre os espaços urbanos.

Cidades sempre foram áreas de interação, diversidade social e transação, "mercado" no sentido explícito do termo. É papel de um urbanismo contemporâneo exercer as possibilidades que surgem com as tecnologias atuais. Apesar das implicaçóes que o contexto cultural e tecnológico traz para o ambiente construído, arquitetos e urbanistas não estão muito presentes neste debate.

Considerar a cidade como uma rede social digital significa projetar um mapa das realidades locais na Internet e disponibilizar uma grande riqueza de conhecimento distribuído. A cidade seria um exemplo de aplicação on-line baseada em redes sociais, uma rede social cujo âmbito não é apenas encontrar amigos, postar fotos e vídeos e procurar trabalho, mas se tornar um protagonista do território e representar a sua complexidade.

\section{Referências}

Batty, M. (2007). Model cities. Available at: http://eprints.ucl. ac.uk/3378/.

Benkler, Y. (2006). The Wealth of Networks: How Social Production Transforms Markets and Freedom. Yale University Press, New Haven.

Goodchild, M.F. (2007). Citizens as sensors: the world of volunteered geography. GeoJournal, 69(4), pp.211-221.

Gordon, E., de Souza e Silva, A. (2011). Net locality: why location matters in a networked world. Wiley-Blackwell, Chichester.

Greenfield, A., 2006. Everyware the dawning age of ubiquitous computing, Berkeley, New Riders; Pearson education.

Harvey, D. (1993). Condição pós-moderna: uma pesquisa sobre as origens da mudança cultural. Ed. Loyola, São Paulo.

Isikdag, I. et al. (2011). An opportunity analysis on the future role of BIMs in urban data management. In Urban and Regional Data Management - UDMS Annual 2011. London: Taylor \& Francis. p. 25-36.

Kitchin, R. \& Dodge, M., 2011. Code space software and everyday life. Cambridge, MIT Press.

Latham, R. \& Sassen, S., (2005). Digital Formations: Constructing an Object of Study. In Digital Formations: Information Technology and New Architectures in the Global Realm. New Jersey: Princeton University Press.

Mitchell, W. (2000). City of bits : space, place, and the infobahn 7a. ed., Cambridge: MIT Press. Available at: http://mitpress. mit.edu/e-books/City_of_Bits/index.html.

Pereira, G.C. (2008). Habitação e Infra-Estrutura Urbana na Região Metropolitana de Salvador. In Como Anda Salvador e sua regiâo metropolitana. pp. 137-155.

Rocha, M. C., Florentino, P. Pereira, G. C. (2014). City as Commons: Study of Shared Visions by Communities on Facebook. Lecture Notes in Computer Science, v. 8580, p. 486-501.

Sassen, S. (2001). The City: Between Topographic Representation and Spatialized Power Projects. Art Journal, 60(n.2), pp.12-20.

Singleton, A. \& Longley, P. (2009). Virtual Geodemographics: Repositioning Area Classification for Online and Offline Spaces. Available at: http://www.bartlett.ucl.ac.uk/casa/ publications/working-paper-147.

Söderström, O. (1996). Paper Cities: Visual Thinking in Urban Planning. Ecumene London 3(3), 249-281.

Tufte, E. (2002). Visual Explanations: Images and Quantities, Evidence and Narrative. Cheshire, Connecticut: Graphics Press. 